\title{
STUDY OF EXTRA CLEANING OF RAPESEEDS IN AN ELECTRIC FRICTIONAL SEPARATOR
}

\author{
Stepan Kovalyshyn ${ }^{1}$, Oleksiy Shvets ${ }^{1}$ \\ ${ }^{1}$ Faculty of Mechanics and Power Engineering, Lviv National Agrarian University, Ukraine
}

\begin{abstract}
KOVALYSHYNSTEPAN, SHVETS OLEKSIY.2018. Study of Extra Cleaning of Rapeseeds in an Electric Frictional Separator. Acta Universitatis Agriculturae et Silviculturae Mendelianae Brunensis, 66(3): 677-683.

The work is devoted to the study of the process of additional cleaning of rape seeds on an electric frictionalseparator, whereaninclinedplanemovinginelectricfieldactsastheworkingbody.Theoretical studies have established that effective cleaning of this culture occurs when the trajectories of motion and the coordinates of the ascension of the components of the seed mixture from the separation plane differ as one another. As a result of the experiments, it was established that the main factors influencing the movement of components of the seed mixture of rape along the separation plane of the electric frictional separator and their orientation are the angle of inclination of the separation plane in the space $\alpha$ (deg.), its velocity $\mathrm{V}_{\text {П }}(\mathrm{m} / \mathrm{s})$, and electric field strength $\mathrm{E}(\mathrm{kV} / \mathrm{cm})$.

As a result of the research it was established that the maximum difference of the coordinates of the ascension of components of a seed mixture of rape from the separation plane can be reached at its angle of inclination in the space $\alpha=9$ deg., its velocity $V_{\Pi}=0.07 \mathrm{~m} / \mathrm{s}$ and the intensity of the electric field $\mathrm{E}=1.8 \ldots 2 \mathrm{kV} / \mathrm{cm}$. Of the factors mentioned above, the most significant influence on the behavior of rape seed on the separation plane and their coordinate is the magnitude of the electric field intensity in the working area of the separator.

The mathematical expressions for determining the basic geometric dimensions of the separation plane of the electric friction separator are identified in this work, which are one of the necessary conditions for the working out and design of the construction of its industrial sample.
\end{abstract}

Keywords: rapeseeds, mixture components, separation, electric field of corona discharge, electric frictional separator, adjustable parameters, geometric dimensions of separation plane

\section{INTRODUCTION}

The yield of crops depends on the quality of seeds, which is determined by its purity and germination. For sowing winter rape seeds we require the first class of purity, not less than $98 \%$ and $97 \%$ for spring rape, that means for $1 \mathrm{~kg}$ of mixture the weed seed content should be no more than 80 pieces and 120 pieces respectively. Germination of seed should be at least $90 \%$ for winter and $85 \%$ for spring rape (Kovalyshyn et al., 2017; Strany, 1980). To ensure such a level of quality seed becomes possible in the process of post-harvest treatment, in which a decisive role makes its additional purification (Aniskin, 1987). However, to separate completely different kinds of injured, feeble seeds and impurities of their hard-to-divide weeds such as cleavers' peas and hairy vetch on existing machines is nearly impossible. This is due to the similarity of physical and mechanical properties of rape seeds and these of impurities.

In order to significantly increase the effectiveness of separation of rapeseed we may use during its additional cleaning an electric frictional separator in which as the working body acts a friction inclined plane moving in the electric field of corona discharge (Kovalyshyn et al., 2017; Shvets, 2013).

But to justify the possibility of practical use of an electric frictional separator in preparation technology of rapeseed cleaning from its hard-to-divide impurities and seeds with low sowing 
qualities (shrunken, injured) we should thoroughly investigate the process of separation of the seed mixture by its mathematical modelling and a series of experimental studies. These studies should aim to establish optimal modes of electric separation on the moving friction inclined plane in the electric field of corona discharge, defining its rational geometric dimensions and parameters which determine its location in space.

\section{MATERIALS AND METHOD}

The main features, by which the separation of seed mixtures on frictional separators is carried out are: the state of the surface of seeds, coefficients of friction material on the working bodies, geometric dimensions and weight of the mixture components. However, they do not give the desired separation quality (Kovalyshyn et al., 2011; Kovalyshyn et al., 2017; Strany, 1980).

One of the ways to improve the efficiency of friction separators is to overlay on the separation plane an electric field of corona discharge. A number of works were devoted to research the work of electric frictional separators (Kovalyshyn et al., 2008; Kovalyshyn et al., 2012; Kovalyshyn et al., 2011; Kovalyshyn et al., 2013; Kovalyshyn et al., 2015; Shvets, 2009; Shvets et al., 2013; Shvets et al., 2014). There the corona discharge of electric field is considered as an additional operating body or power action that allows to take into account, in addition to the physical and mechanical, the biological characteristics of the components of the seed mixture.

In the work (Kovalyshyn et al., 2017; Nishchenco et al., 2009) we proposed a mathematical model that describes the motion of a spherical shape particles moving in an electric field on friction inclined plane:

$$
\begin{aligned}
& \chi_{1}=V_{\ddot{I}} t \cos \left(\vec{V}_{\hat{I}}^{\wedge} x_{1}\right)+x \\
& y_{1}=V_{\ddot{I}} t \cos \left(\vec{V}_{\tilde{I}}^{\hat{I}} y_{1}\right)+y \\
& z_{1}=R
\end{aligned}
$$

where $x, y,-$ coordinates of the centre of mass of the ball to any point in time; $V_{\Pi}$ - speed of the separation plane; $t$ - time of the seed's movement; $\left(\vec{v}_{\hat{I}} x_{1}\right)$ and $\left(\vec{v}_{\hat{I}} y_{1}\right)$ - the angle between the vector of speed of the plane and the vector direction of the ball in a fixed coordinate system ; $R$ - radius of the seed.

Equations (1) help us to calculate the coordinates of trajectories of seeds on the working surface of the separator at different adjustable parameters of separation, such as the angle of inclination of the separation plane $\alpha$ (degrees), its velocity of movement $V,(\mathrm{~m} / \mathrm{s})$ and the electric field $E$, $(\mathrm{kV} / \mathrm{cm})$ (Kovalyshyn et al., 2008; Kovalyshyn et al., 2013; Shvets, 2013; Shvets et al., 2017).

Examining the impact of adjustable parameters on the trajectory and the descending coordinates of the components of seed mixtures we can determine the optimal values of these parameters under which the process of separating of hard-todivide impurities and various injured seeds will be the most effective.

Having solved by numerical methods the equation ( 1 ) in the MATLAB environment we obtained the value for the running coordinates of movement of particles of the seed mixture on the separating surface of the electric frictional separator and built their calculated motion paths.

\section{RESULTS}

The impact on the seeds' action of the separation plane inclination angle $\alpha$ at constant values of its velocity $(V=$ const) and electric field $(E=$ const $)$ allows us to set the analysis of the trajectories shown in Fig. 2.

Analyzing the given path we can state that the minimum value of the angle of inclination of the plane corresponds to the maximum $y$ coordinate of the seed's trajectory.

The trajectory of seed is also affected by the speed of the separation plane. This is confirmed by the calculated trajectories of seeds on it by its values varying within $0.03 \ldots 0.12 \mathrm{~m} / \mathrm{s}$ (Fig. 3).

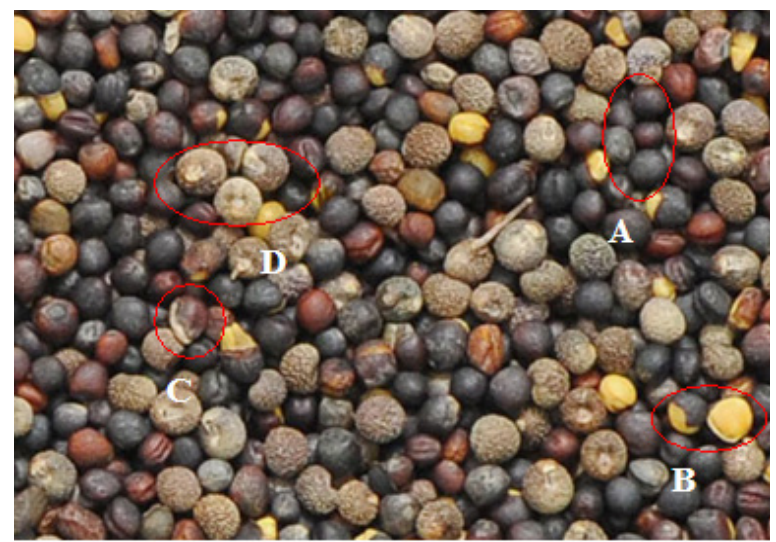

1: Rape seed mixture: A-quality seed; B - injured seed; C-feeble seed; D-cleavers' seed 
Increase of speed $V_{\Pi}$ increases the seed's descend from the plane coordinates $y$ of a seed. The value of coordinates $x$ velocity of the plane has no significant effect.

The most significant impact on the seed' action which is on the separation plane has the value of the electric field in the working area of the separator. Proof of this is derived from the calculated trajectory of the seeds in an electric field on an inclined plane by the values of $E$ field strength within 0.71 to 2.14 $\mathrm{kV} / \mathrm{cm}$ (Fig. 4).
Analysis of Fig. 4 showed that the increase of the electric field in the working area of the separator leads to significant differences of the coordinate values of $x$ and $y$ descend of seeds from the separation plane. The reason for this is the impact on them of an additional electric power. This factor suggests the possibility of effective separation of the components of seed mixtures. As the cultivated seed and seed of weeds belong to different species, their electrical properties are different. So they will get a different charge and different ways to interact

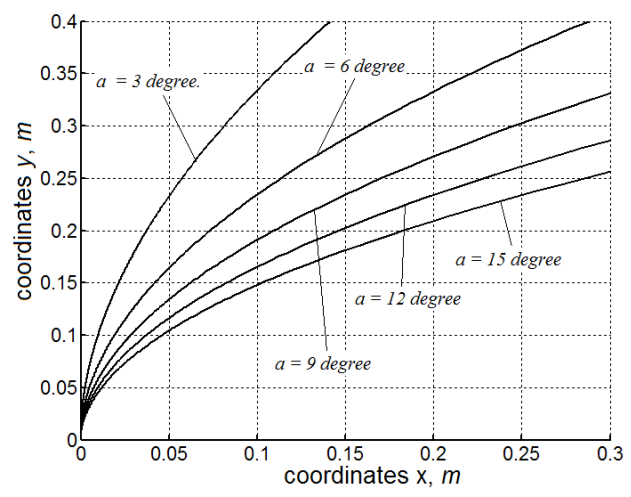

2: Dependence of the trajectory of rape seeds moving on an inclined plane in an electric field on the angle of inclination $\alpha(V \Pi=$ const, $\mathrm{E}=$ const $)$

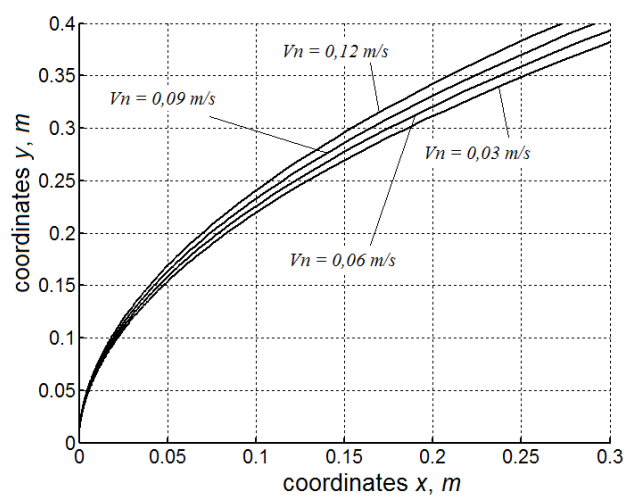

3: Dependence of the trajectory of rape seeds moving on an inclined plane in an electric field on the speed $V_{\Pi}(\alpha=c o n s t, \beta=c o n s t, E=c o n s t)$

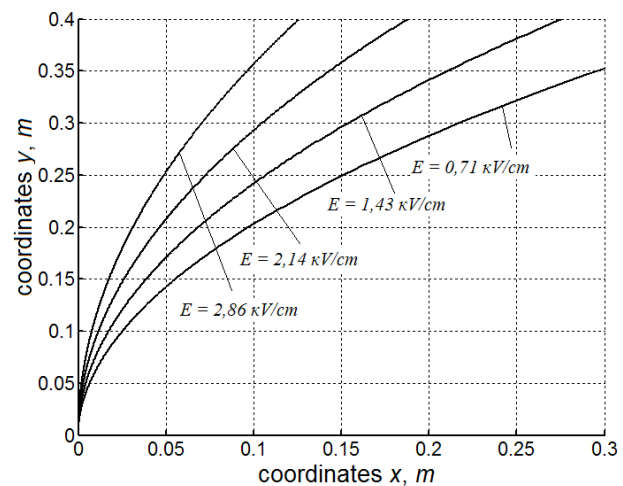

4: Dependence of the trajectory of rape seeds moving on an inclined plane in the electric field of the electric field $E$ ( $\alpha=$ const, $\beta=$ const, $V_{\Pi}=$ const) 
with the working body of the separator. Under these conditions, they will move in different trajectories, which is proving Fig. 4. Under these conditions, you can expect a positive result from the process of separation of hard-to-divide impurities and various mixtures of damaged seeds of rape.

In research of seeds' trajectories on electric frictional separator's screen an important issue is the study of geometric parameters of the separation plane. Their optimal values depend on the quality of separation process performance, the ability to realize the impact of adjustable parameters on separation efficiency of rape seed mixtures.

In the process of separation of seed the rape mixture enters the separator's working surface with an initial velocity $V_{0}$. This surface moves at a constant speed $V_{\Pi}$. The general index of the mixture divisibility by the set of physical and mechanical and electrical properties of its components is the angle of equilibrium $\alpha_{e}$ (Kovalyshyn et al., 2008; Nishchenco et al., 2009). Once on the sloping surface of the screen, seeds move through it at some trajectories with different accelerations $\mathrm{g}_{1}$ :

$g_{1}=g \cdot \sin \alpha_{e}$,

where $g$ - acceleration of gravity, $\mathrm{m} / \mathrm{s}^{2} ; \alpha_{e}$ - the angle of equilibrium of seeds, degrees.

If the working surface is imposed to a moving coordinate axis $O_{x y z}$ so that the axis $O_{x}$ is directed down along the line of the greatest slope of the screen, and by the particle of the seed mixture consolidate a fixed reference system $O_{x 1 y 1 z}$, then in the initial time line the direction of instantaneous relative speed of seed $V_{r}$ will form with the axis $O_{y}$ some angle $\theta$ (Fig. 5).

Taking the angle $\theta$ between the direction of the instantaneous relative velocity $V_{r}$ and the line of seed's largest inclination as a function of displacement $S$ seeds we can find the velocity of the centre of their masses with the arbitrary values of the angle (Nishchenco et al., 2009).

$$
V=V_{0} \cdot\left(\frac{\sin \theta_{0}}{\sin \theta}\right)^{\frac{1}{1,4}} \cdot\left(\frac{\operatorname{tg} \frac{\theta}{2}}{\operatorname{tg} \frac{\theta_{0}}{2}}\right)^{\frac{a}{1,4}}
$$

where $V_{0}$ - initial velocity of the seed, m/s; $b$ - integral index of divisibility, which depends on a combination of physical and mechanical and electrical properties of seeds:

$B=\frac{\delta}{g_{1} \cdot R} \cdot\left(g \cos \alpha_{p}+\frac{F_{e}}{m}\right)$

where $\delta$ - coefficient of rolling friction; $R$ - radius of seeds, $\mathrm{m} ; \mathrm{m}$ - seed's weight, $\mathrm{kg}$; $F_{e}$ - the value of electric power, $N$.

Moving along this separation plane the particles of the seed mixture will move along curved trajectories relative to its original position. The speed of their movement along the separation plane will be, accordingly, defined by the projections of relative speed of the centre of mass of seeds:

$$
\begin{aligned}
& V_{y}=V \cdot \cos \theta \\
& V_{x}=V \cdot \sin \theta
\end{aligned}
$$

\section{DISCUSSION}

If the components of rape seed mixtures possess different values of angles $\alpha_{e}$ of equilibrium, and $\alpha_{e 1}<\alpha_{e 2}<\ldots<\alpha_{e c}$, over the same period of time $t$ they will go a different way

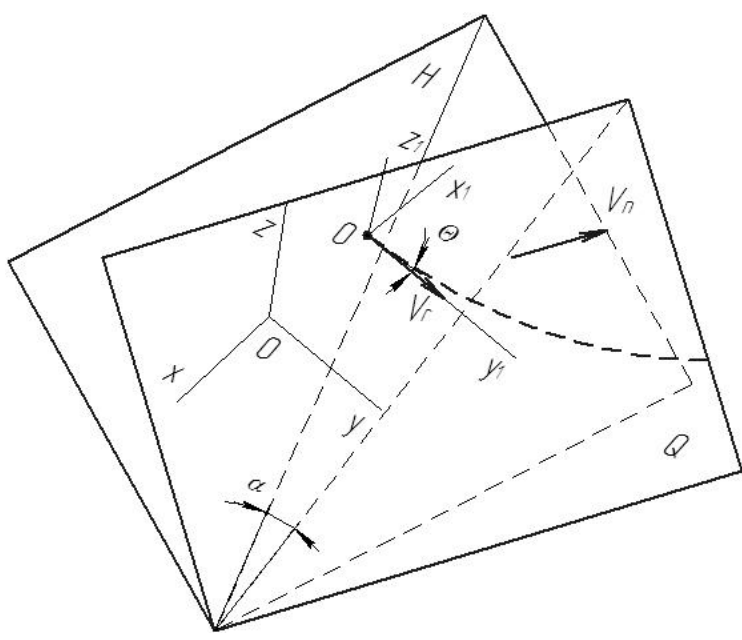

5: Placement of separation plane in space

oxyz - the axis of the fixed reference system; $o_{1} x_{1} y_{1} z_{1}$ - the axis of the mobile reference system; $Q$ - moving friction plane; $\mathrm{H}$ - horizontal projection of moving friction plane; $\alpha$ - angle of inclination of the frictional plane to the horizon; $\mathrm{Vn}$ - vector of the velocity of motion of the friction plane; $\mathrm{Vr}$ - vector of the relative speed of the seed; $\theta$ is the angle between the direction of the instantaneous relative speed of the seed Vr and the axis oyl 
because the equilibrium angle affects the value of the acceleration of seed $g_{1}$.

In the case when of seed mixtures we should select seeds of cleaver for which the equilibrium angle is greater than the angle of equilibrium of rapeseed $\left(\alpha_{e c}>\alpha_{e r}\right)$ (Kovalyshyn et al., 2017, Kovalyshyn et al., 2015), then the largest tilt angle of the separator's screen must not exceed $\alpha_{e r}$. The path, which the rape seed overcome over time $t$, will be determined by the coordinates:

$$
\begin{aligned}
& y_{\partial}=\frac{V_{\partial}^{2}}{g_{1 \delta}} \\
& x_{\partial}=\frac{y_{\partial} \cos \theta_{h}}{\sin \theta_{h}}
\end{aligned}
$$

where $h$ - interval of the angle change $\theta$.

Seeds of cleaver with angle of equilibrium $\alpha_{e c}$ will, accordingly, go the way:

$y_{n}=\frac{V n^{2}}{g_{1 n}}$ and $x_{n}=\frac{y_{n} \cdot \cos \theta_{h}}{\sin \theta_{h}}$

By the analogous equations will be described the trajectories of shrunken and injured seeds.

Theoretically the value $y_{r}$ (Fig. 6) will characterize the required width of a separator's screen from the supply of seats of the rising mixture to its lower edges, ie to the place seeds descend from the screen.

Taking into consideration that each group of seeds has some deviation from the mean for its equilibrium angle $\alpha_{e}$ that can affect the quality of the division, and we will need to slightly increase the width of the screen, taking it equal:
$Y=y_{e}+y_{0}$, where $y_{0}=0,1 \ldots 0,2 \mathrm{~m}$

Thus, seeds of rape, having anequilibrium angle $\alpha_{e}<\alpha_{\text {max }}$ at the time $t_{1}$ should leave the side edges of the screen. For this they must fulfil the condition:

$\vec{V}_{n}+\vec{V}_{\Pi} \neq 0$

Along with the motion down an inclined plane of the separator the seeds will move together with the screen in the axis $O_{x}$ with velocity $V_{\Pi}$. The path that they overcome will be determined from the equations (6) and (7).

As mentioned earlier, the clover seeds with a maximum angle of equilibrium $\alpha_{\mathrm{e} \max }$ after the time $t_{1}$ will move along the axis $O_{x}$ with velocity of the screen $V_{\Pi}$. That is why the length of the screen $l_{\mathrm{p}}$ from the feeding place to the axis driving the roller should be equal to or greater than $y_{n}$, ie:

$l_{p} \geq \frac{y_{n} \cdot \cos \theta_{h}}{\sin \theta_{h}}$

Taking the length of the feeding line as $l_{1}$, and the distance from the edge of the line to the roller axis driven by $l_{0}$, we get the total length of the working leg of the separator's screen, ie distance between the axles of the rollers:

$L=l_{0}+l_{1}+l_{p}, \mathrm{~m}$.

The obtained equations can determine the main design parameters of the working surface of electric frictional separator and can serve as a baseline for the development of design production samples of this type of separators.

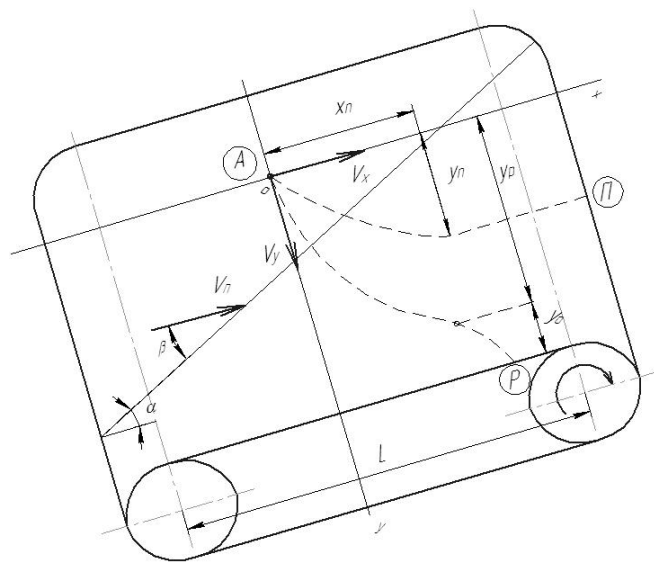

6: Scheme determining the parameters of the screen of electric frictional separator

xoy - the axis of the fixed reference system; $\alpha$ - angle of inclination of the frictional plane to the horizon; $\beta$ is the angle between the line of inclination of the friction plane to the horizon and the direction of its movement; Vx is the vector of the velocity of the motion of the seed relative to the axis ox; Vy - vector of seed speed relative to the axis oy; $\mathrm{Vn}$ - vector of the velocity of motion of the friction plane; A - the point of feeding of the seed on the plane; $\Pi$ - the point of the ascension of the seed of the cleavers from the plane; $\mathrm{P}$ - the point of the ascension of rape seed from the plane; $\mathrm{xn}$, $\mathrm{yn}$ - coordinates of the movement of the seeds of the cleavers; $\mathrm{xr}, \mathrm{yr}$ - coordinates of the movement of rape seeds; $\mathrm{y} 0=0,1$ ... $0,2 \mathrm{~m} ; \mathrm{l}$ - the length of the plane 


\section{CONCLUSIONS}

1. Presented in the results of theoretical researches of winter rape seed mixtures separation process on an inclined plane with electric field will determine the effects of adjustable parameters - the angle of inclination of the plane $\alpha$ (degrees), its velocity $V_{\Pi}(\mathrm{m} / \mathrm{s})$ and the electric field $E,(\mathrm{kV} / \mathrm{cm})$ at the trajectory and the coordinates of components' descend of the seed mixtures.

2. The most significant impact on the action of the seeds that are on separation plane has the value of the electric field in the working area of the separator. As the cultivated seed and weeds belong to different species, their electrical properties are different. It is due to this factor it is possible to change the value of the electric field in different ways to influence the interaction forces of the components of seed mixtures with electric separator's working body as a condition of their effective separation. 3. Justificated geometrical parameters of the separating plane of electric frictional separator greatly affect the quality of separation efficiency of the process and can serve as a baseline for the development of design production samples of this type of separators.

\section{Acknowledgements}

The presented work was performed in accordance with the research development "Development of new technologies and technical means for the preparation of small-seeded mixtures with the help of controlled electromagnetic actions" (state registration number: 0117 U 003081). Funded by the Ministry of Education and Science of Ukraine.

\section{REFERENCES}

ANISKIN, V. 1987. On improving the quality of seeds ways of postharvest and pre-processing. Prepare seeds in intensive grain production: Coll. scientific.tr. VIM, 112(3): 20.

KOVALYSHYN, S., NISHCHENKO, I. and SHVETS, O. 2008. Investigation of winter rape seed of separation moving in an electric field downhill. In: Materials of the $9^{\text {th }}$ International Scientific and Practical Conference dedicated to the memory of academician P. Vasilenko. Lviv National Agrarian University, 17-18 October, pp. 225-230.

KOVALYSHYN, S. and SHVETS, O. 2017. Investigation of equilibrium angles of winter rapeseed onan inclined plane of an electro frictional separator and optimization of theirgeometrical sizes. Teka. Commission of motorization and energetics in agriculture, 17(1): 45-52.

KOVALYSHYN, S. and SHVETS, O. 2012. The results of the research process of extra cleaning of winter rapeseed at electric friction separator. In: Proceedings, Agricultural machinery and technology. Ruse University "Angel Kanchev", Ruse, pp. 56-60.

KOVALYSHYN, S. and SHVETS, O. 2011. Utilisation of electric field of corona discharge for the preparation of winter rapeseed reproductive material. Motorol. Agriculture Motorisation and Power Engineering, 13:276-283.

KOVALYSHYN, S., SHVETS, O., DADAK, V. and HUSAK. Y. 2017. Improvement of post-harvest technology of winter rape seeds. In: Engineering of agricultural and forestry production: annotations of papers and experts presented on the occasion of the 40th anniversary of the Faculty of Production Engineering of SGGW in Warsaw. SGGW, 8-9 June. Warsaw: SGGW in Warsaw, pp. 29-30.

KOVALYSHYN, S., SHVETS, O., GRUNDAS, S. and TYS, J. 2013. Use of the electro-separation method for improvement of the utility value of winter rapeseeds. Int. Agrophys., 27: 419-424.

KOVALYSHYN, S., SHVETS, O., SALO, Y. A. and KUZMA, Y.A.-R. 2015. Impact of additional electric power efficiency separation on rapeseed in the electric separator. Magazine "Agro-engineering investigations, 19: 45-51.

KOVALYSHYN, S., SHVETS, O. and SOSNOWSKI, S. 2017. The justification of the parameters of the dosage device for the electric frictional. An international journal on operation of farm and agri-food industry machinery, 19(4): 69-72.

NISHCHENCO, I. and SHVETS, O. 2009. The investigation of the movement trajectory of seed mixture particles of the globe-shape form along the movable in the electric field of the friction flat. Bulletin of the Dnipropetrovsk State Agrarian University. Special edition, 2(09): 256-259.

SHVETS, O. 2013. Analysis of the mathematical description of the motion of rapeseed in separation plane electric friction separator. Bulletin of the Lviv National Agrarian University "Agro-engineering investigations, 17: 144-149.

SHVETS, O., DADAK, V. and HUSAK, Y. 2017. The use of an electric field as an additional body of work during additional cleaning of seeds of agricultural cultures. In: Annotations of papers and potters presented at the 15th International Scientific and Technical Conference Motorization and Energetics in Agriculture MOTROL 2017. Poiska Academy of Sciences (Branch in Lublin), 30 June - 01 July, Lublin, Poland.

SHVETS, O. and DUHANETS, V. 2014. The research results trajectories of rape seeds moving on an inclined plane. Bulletin of the Lviv National Agrarian University Agro-engineering investigations, 18: 148-152.

STRANY, I. 1980 Industrial seed: Handbook. Moscov: Kolos. 
